\title{
Three-North Shelter Forest Program contribution to long-term increasing trends of biogenic isoprene emissions in northern China
}

\author{
Xiaodong Zhang ${ }^{1}$, Tao Huang ${ }^{1}$, Leiming Zhang ${ }^{2}$, Yanjie Shen ${ }^{1}$, Yuan Zhao ${ }^{1}$, Hong Gao ${ }^{1}$, Xiaoxuan Mao ${ }^{1}$, \\ Chenhui Jia ${ }^{1}$, and Jianmin $\mathbf{M a}^{1,3}$ \\ ${ }^{1}$ Key Laboratory for Environmental Pollution Prediction and Control, Gansu Province College \\ of Earth and Environmental Sciences, Lanzhou University, Lanzhou, China \\ ${ }^{2}$ Air Quality Research Division, Environment Canada, Toronto, Ontario, Canada \\ ${ }^{3}$ CAS Center for Excellence in Tibetan Plateau Earth Sciences, Beijing, China
}

Correspondence to: Jianmin Ma (jianminma@lzu.edu.cn)

and Tao Huang (huangt@lzu.edu.cn)

Received: 21 November 2015 - Published in Atmos. Chem. Phys. Discuss.: 21 January 2016

Revised: 3 May 2016 - Accepted: 18 May 2016 - Published: 7 June 2016

\begin{abstract}
To assess the long-term trends of isoprene emissions in northern China and the impact of the Three-North Shelter Forest Program (TNRSF) on these trends, a database of historical biogenic isoprene emissions from 1982 to 2010 was developed for this region using a biogenic emission model for gases and aerosols. The total amount of the biogenic isoprene emissions during the 3 decades was $4.4 \mathrm{Tg}$ in northern China and $1.6 \mathrm{Tg}$ in the TNRSF, with annual emissions ranging from 132000 to $176000 \mathrm{tyr}^{-1}$ and from 45000 to $70000 \mathrm{t} \mathrm{yr}^{-1}$, respectively, in the two regions. Isoprene emission fluxes have increased substantially in many areas of the TNRSF over the last 3 decades due to the growing trees and vegetation coverage, especially in the central north China region where the highest emission incline reached to $58 \%$ from 1982 to 2010. Biogenic isoprene emissions produced from anthropogenic forests tended to surpass those produced from natural forests, such as boreal forests in northeastern China. The estimated isoprene emissions suggest that the TNRSF has altered the long-term emission trend in north China from a decreasing trend during 1982 to 2010 (slope $=-0.533, R^{2}=0.05$ ) to an increasing trend for the same period of time (slope $=0.347, R^{2}=0.014$ ), providing strong evidence for the change in the emissions of biogenic volatile organic compounds (BVOCs) induced by the human activities on decadal or longer timescales.
\end{abstract}

\section{Introduction}

While trees and plants can efficiently remove pollutants from the atmosphere (Nowak et al., 2006, 2014; Myles et al., 2012; Camporn, 2013; Fenn et al., 2013; Adon et al., 2013; Zhang et al., 2015), they also play a role in air pollution through atmospheric chemistry. It has been widely acknowledged that terrestrial ecosystems release large quantities of reactive biogenic volatile organic compounds (BVOCs) into the atmosphere as a significant product of biosynthetic activities of trees and plants (Purves et al., 2004; Zemankova and Brechler, 2010). BVOCs play important roles in tropospheric chemistry, carbon budget, and global climate change (Purves et al., 2004; Nichol and Wong, 2011; Aydin et al., 2014). For example, BVOCs are precursors of surface ozone formation in the presence of nitrogen oxide $\left(\mathrm{NO}_{x}\right)$ (Penuelas et al., 2009; Penuelas and Staudt, 2010). It has been shown that VOC emissions from biogenic sources have far exceeded those from anthropogenic sources (Guenther et al., 1995; Aydin et al., 2014).

Among the three dominant VOCs (isoprene, monoterpenes, oxygenated compounds) contributing to BVOC emission fluxes, isoprene accounts for $70 \%$ of the total BVOC emissions globally (Guenther et al., 2006; Helmig et al., 2013; Aydin et al., 2014) and about 50\% in China (Song et al., 2012; Li et al., 2013). In particular, terrestrial plant foliage is thought to be the major source of atmospheric isoprene which releases over $90 \%$ of isoprene from global 
forests (Lamb et al., 1987; Guenther et al., 2006). Extensive investigations have been conducted over the past several decades to assess BVOC emissions and their potential influences on tropospheric chemistry and the carbon cycle (Lamb et al., 1987; Geron et al., 2006; Müller et al., 2008; Chang et al., 2009; Pacifico et al., 2009; Zemankova and Brechler, 2010; Guo et al., 2013; Calfapietra et al., 2013). Efforts have been also made to measure and simulate BVOC emissions in China (Wei et al., 2007; Chen et al., 2009; Song et al., 2012; Li et al., 2013). A recent study by Song et al. (2012) revealed that the annual BVOC emissions in eastern China was $11.3 \times 10^{6} \mathrm{t}$, of which $44.9 \%$ was isoprene, followed by monoterpenes at $31.5 \%$, and other VOCs at $23.6 \%$. The study also showed high isoprene emissions in boreal forests in northeastern China, on the Qinling-Ta-pa mountains in central China, and in southern China. Li et al. (2013) estimated China's total BVOC emissions as $42.5 \mathrm{Tg}$ in 2003, of which $55 \%$ was isoprene emission.

BVOC emissions are often thought to be static on decadal or longer timescales because forest coverage from regional to global scales is assumed to be at steady state (Sanderson et al., 2003; Purves et al., 2004). However, there are concerns for the potential impacts of climate change and changes in underlying vegetation coverage on isoprene emissions because leaf-level emission intensity depends on biological and meteorological conditions (Turner et al., 1991; Constable et al., 1999; Ashworth et al., 2010; Arneth et al., 2008, 2011). Several modeling studies were conducted to assess the interactions between biogenic isoprene emissions and climate change as well as the human activities (Constable et al., 1999; Sanderson et al., 2003). Using the USDA (the United States Department of Agriculture) Forest Service Inventory Analysis (FIA), Purves et al. (2004) estimated decadal changes in BVOC emissions in the eastern US between the 1980s and 1990s caused by changes in the extent, structure, and species composition of forests. They attributed these changes to human-induced deforestation and reforestation. Arneth et al. $(2008,2011)$ compared the responses of the simulated BVOC emissions derived using different models to climate and vegetation changes. They found that increasing forest area could add several tens of percent to future isoprene emissions. Climate change could also exert influences on isoprene emissions via the changes in temperature and $\mathrm{CO}_{2}$. The latter can benefit forest productivity and leaf growth via fertilization effect. Steiner et al. (2002) simulated the effect of human-induced land use changes due to urbanization and agriculture on BVOC emissions. Their results revealed that the increasing anthropogenic emissions of VOCs subject to urbanization overall enhanced total VOC emissions. Most of the existing studies were carried out using climate models subject to projected climate and land cover change scenarios.

The three northern regions shelter forest (TNRSF) program in China, also known as "the Green Great Wall", began in 1978 and will terminate in 2050. Figure 1 illustrates the
TNRSF regions, including 11 provinces and two megacities, Beijing and Tianjin, as highlighted in the figure caption and marked in the figure. The program aims to increase China's forest coverage from $5 \%$ in the 1970 s to $15 \%$ by 2050 . By the end of the fourth phase of the program in 2010, the vegetation coverage over the TNRSF had already reached $12.4 \%$ (Wang et al., 2011; Central Government of China, 2012). The program has achieved great successes in mitigating local ecological environment and climate, despite the debates on the effectiveness of the TNRSF in improving the ecological environments in northern China and negative influences of the program on groundwater storage in arid and semi-arid regions (Pang, 1992; Cheng and Gu, 1992; Parungo et al., 1994; Hu et al., 2001; Zhong et al., 2001; Ding et al., 2005; Liu et al., 2008; Yan et al., 2011; Zheng and Zhu, 2013; Fang et al., 2001; Tan et al., 2007; Zhang et al., 2013). Recently, the TNRSF impact on air quality was also investigated (Zhang et al., 2015), which showed that the increased vegetation coverage in the TNRSF has increased its efficiency in removing air contaminants from the atmosphere as supported by the increasing modeled dry deposition velocities and fluxes of sulfur dioxide $\left(\mathrm{SO}_{2}\right)$ and $\mathrm{NO}_{x}$ in many places of the region during the past 3 decades.

Given its unique status in large-scale artificial afforestation in the human history, the TNRSF might provide significant insights into understanding human-induced biogenic VOC emissions on a long-term scale. In the present study, a framework combining satellite remote sensing data, a biogenic emission model, and uncertainty analysis was first developed to estimate BVOC emissions in northern China. Seasonal and annual biogenic isoprene emission inventories were then developed from 1982 to 2010. Finally, the potential influences of the development and expansion of the TNRSF on the longterm trends of the biogenic isoprene emissions were investigated to discern evidence of decadal or longer-term changes in BVOC emissions from large-scale forest restorations induced by the human activities. The newly generated historical isoprene emissions inventories over northern China will also be useful for assessing past, current, and future air quality and climate issues.

\section{Methodology}

\subsection{BVOC emission model}

The MEGAN2.1 (Model of Emissions of Gases and Aerosols from Nature version 2.1) (Guenther et al., 2012) which is an updated version of MEGAN2.0 (Guenther et al., 2006) and MEGAN2.02 (Sakulyanontvittaya et al., 2008), was used here to estimate BVOC emissions in northern China. This new version includes additional compounds, emission types, and various controlling processes. For BVOC emissions, MEGAN2.1 is primarily driven by biological and meteorological factors, including vegetation type with which the 


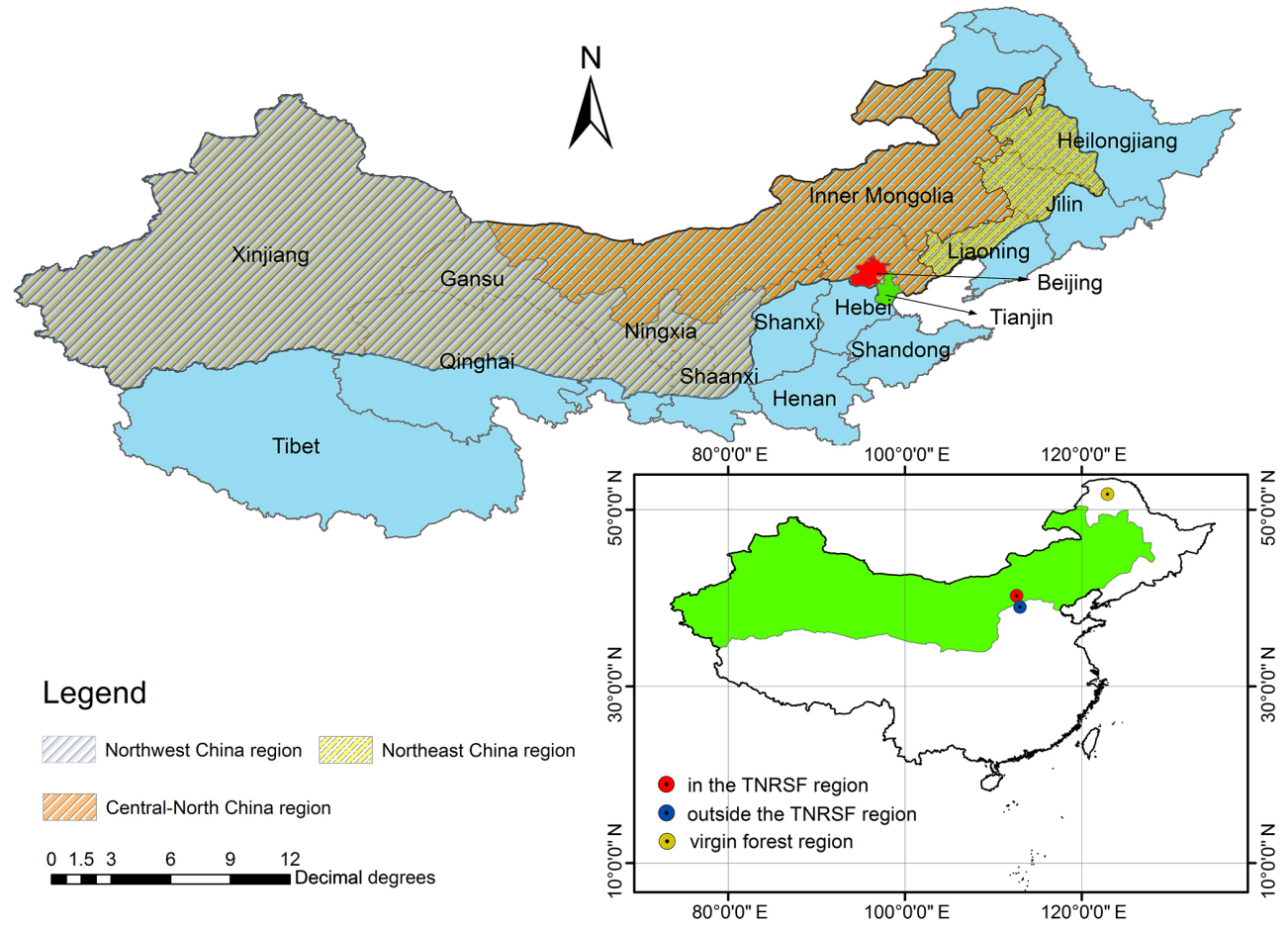

Figure 1. The Three-North Shelter Forest Program (TNRSF) in northern China (defined also by green color in the inner figure (right lower corner of Fig. 1) and three regions of the TNRSF. The northwest China region of the TNRSF, defined by grey color, includes Xinjiang, Gansu, the north of Qinghai, Ningxia, west inner Mongolia, and the north of Shaanxi, many places in this part of the TNRSF, particularly in Gansu, Ningxia, and west inner Mongolia, are not covered by forest but by shrubs; the central north China region, defined by orange gold color, includes the north of the Shanxi and Hebei provinces, Beijing, Tianjin, and central inner Mongolia; the northeast China region, defined by brass color, includes east inner Mongolia, parts of the Liaoning, Jilin, and Heilongjiang provinces. Red, blue, and yellow circles in the inner figure indicate three small areas in the TNRSF, farmland, and the boreal forest from which isoprene emission flux are extracted for comparison (see Results and Discussions sections). Two megacities, Beijing and Tianjin in the central north China region, are also indicated.

emission factors of BVOCs are assigned, air and leaf temperatures, light, leaf age and leaf area index (LAI), solar radiation/photosynthetically active radiation (PAR), wind speed, humidity, and soil moisture (Guenther et al., 2006, 2012; Pfister et al., 2008; Arneth et al., 2011). MEGAN2.1 was set up over northern China with a grid spacing of $0.25^{\circ} \times 0.25^{\circ}$ latitude/longitude to produce gridded daily and monthly emission fluxes. Meteorological data used in the MEGAN2.1 employed the 6-hourly objectively analyzed data from the $1^{\circ} \times 1^{\circ}$ latitude/longitude NCEP (National Centers for Environmental Prediction, 2016) Final Operational Global Analysis. These data were then interpolated into the TNRSF grids on the spatial resolution of $0.25 \times 0.25$ latitude/longitude. PAR was calculated from solar radiation provided by the big-leaf dry deposition model (Zhang et al., 2002). Twentytwo land types were used, including an additional crop type which was not specified in the MEGAN2.1. These land types at each model grid were identified using the surface roughness lengths estimated from satellite remote sensing data (Zhang et al., 2015). Guenther et al. (2012) reported the differences in MEGAN2.1 modeled annual isoprene emissions as a result of changing plant functional type (PFT) (24\%),
LAI (29\%), and meteorology (15\%) input data. This suggests that LAI is one of crucial variables in the model.

\subsection{LAI}

LAI data with $0.25^{\circ} \times 0.25^{\circ}$ latitude/longitude resolution from 1982 to 2010 were derived from the satellite remote sensing data of the normalized difference vegetation index (NDVI) for the same period. Detailed descriptions of the procedures generating LAI data for the TNRSF region were presented in Zhang et al. (2015).

\subsection{Uncertainty analysis}

Although the BVOC emissions model was well established for different vegetation types, there were uncertainties in the estimate of BVOC emission fluxes. Some of these uncertainties are generated from inaccurate emission factors, empirical algorithms, and input data used in the model (Hanna et al., 2005; Guenther et al., 2012). Situ et al. showed that, in addition to the emission factors, PAR and temperature also created large uncertainties in the MEGAN model (Situ et al., 2014). A Monte Carlo technique was used to evaluate 


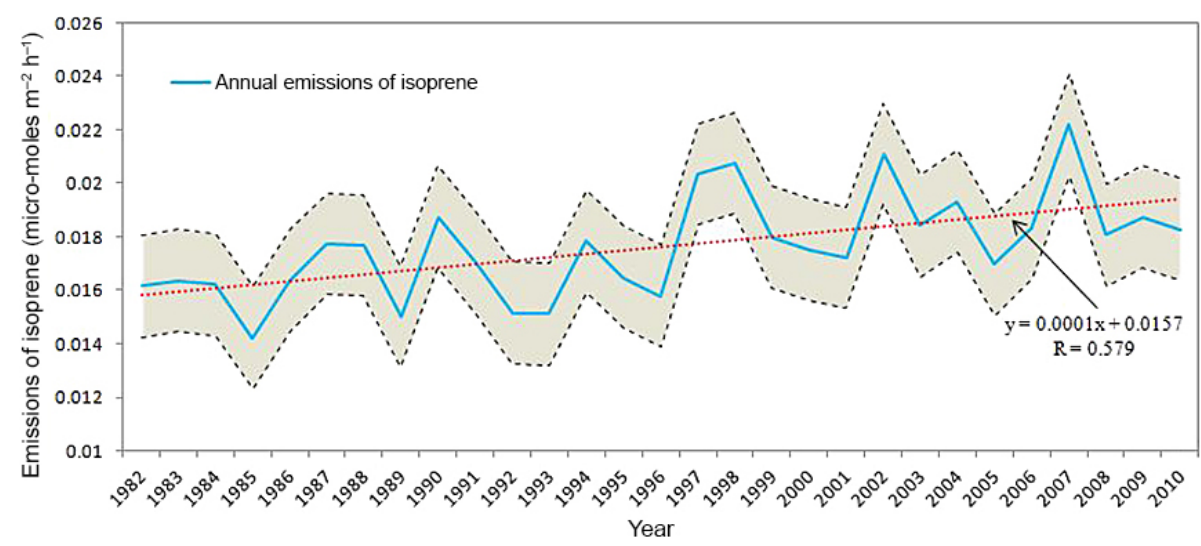

Figure 2. Domain-averaged annual emission flux (micromoles $\mathrm{m}^{-2} \mathrm{~h}^{-1}$ ) of isoprene over the TNRSF from 1982 to 2010 . Red dotted line indicates linear trend of emission fluxes and shading stands for \pm 1 standard deviation of emission fluxes.

uncertainties of modeled isoprene emissions by MEGAN2.1 (Hanna et al., 2005; Guenther et al., 2006, 2012; Situ et al., 2014). In the uncertainty analysis, each input parameter in MEGAN2.1 for isoprene emissions, including LAI, leaf temperature (a function of air temperature), PAR, emission factors, several empirical coefficients related to past leaf temperatures, and solar zenith, was treated as a random variable with a normal distribution. The MEGAN2.1 model for BVOC emissions was run repeatedly 100000 times at the $95 \%$ confidence level based on the coefficients of variation $(\mathrm{CV}, \%)$ of these input parameters. The Monte Carlo simulations showed that the isoprene emissions reached approximately a normal distribution, ranging from 0.05 to $5.29 \mathrm{mi}-$ cromole $\mathrm{m}^{-2} \mathrm{~h}^{-1}$ with the variation from 97 to $211 \%$. Details for the uncertainty analysis are presented in the Supplement (Table S1, Fig. S1).

\section{Results}

\subsection{Isoprene emission inventory in TNRSF}

Figure 2 shows the TNRSF domain-averaged annual biogenic isoprene emissions (micromoles $\mathrm{m}^{-2} \mathrm{~h}^{-1}$ ) aggregated from monthly values. The magnitudes of isoprene emissions estimated in the present study agree with China's BVOC emission inventory established previously, particularly in the natural forests (Song et al., 2012; Li et al., 2013), as elaborated below. A long-term increasing trend up to 2007, although with fluctuations in certain years, was observed (Fig. 2). The emissions in the central north region of the TNRSF exhibited the strongest increasing trend with the highest emission increase by $58 \%$ over the 30 -year period.

Figure S2 illustrates the MEGAN2.1 simulated isoprene emission fluxes across the TNRSF in 1982, the early stage of the TNRSF construction, and 2010, the end of the fourth phase (2001-2010) of the program, respectively. Compared with the emission fluxes in 1982, higher isoprene emissions in the central north China region and lower emission fluxes in the northeast region and eastern inner Mongolia region of the TNRSF were identified in 2010. The differences in the biogenic isoprene emissions between 1982 and 2010 were calculated as $E_{\text {dif }}=E_{2010}-E_{1982}$. The spatial pattern of $E_{\text {dif }}$ (Fig. 3) is consistent with the emission fluxes in 1982 and 2010, as shown in Fig. S2a and b. Positive differences of $E_{\text {dif }}$ were observed in the mountainous areas of west Xinjiang, Shaanxi, eastern Gansu provinces, and the central north China region, suggesting increasing isoprene emissions associated with the expansion of the TNRSF in these regions.

As mentioned previously in the Introduction, in addition to forest expansion, biogenic isoprene emissions are also associated with climate change via changes in mean temperature (Sanderson et al., 2003) and PAR (Guenther et al., 2006, 2012; Situ et al., 2014). Since the influence of climate change on BVOC is beyond the scope of this article, we shall not assess detailed associations between climate change (mean temperature) and isoprene emissions from the TNRSF. Nevertheless, in Sect. 4, we shall briefly discuss the potential influence of the changes in annual mean air temperature and PAR on long-term trends of biogenic isoprene emissions in the TNRSF.

\subsection{Isoprene emission trend in the TNRSF and northern China}

Decadal or longer time trends in isoprene emissions over the TNRSF and northern China can provide some insights into the impact of the large-scale artificial afforestation on BVOC emissions - the knowledge that is needed to address air quality, climate, and ecosystem issues. Figure 4 illustrates modeled isoprene emission fluxes (micromoles $\mathrm{m}^{-2} \mathrm{~h}^{-1}$ ) in 2000 (Fig. 4a), after 20 years of construction of the TNRSF, and the slopes (trends) of the linear regression relationship between isoprene emissions and the time sequence of 1982 2010 (Fig. 4b) over northern China, respectively. High isoprene emissions can be found in the regions extending from 


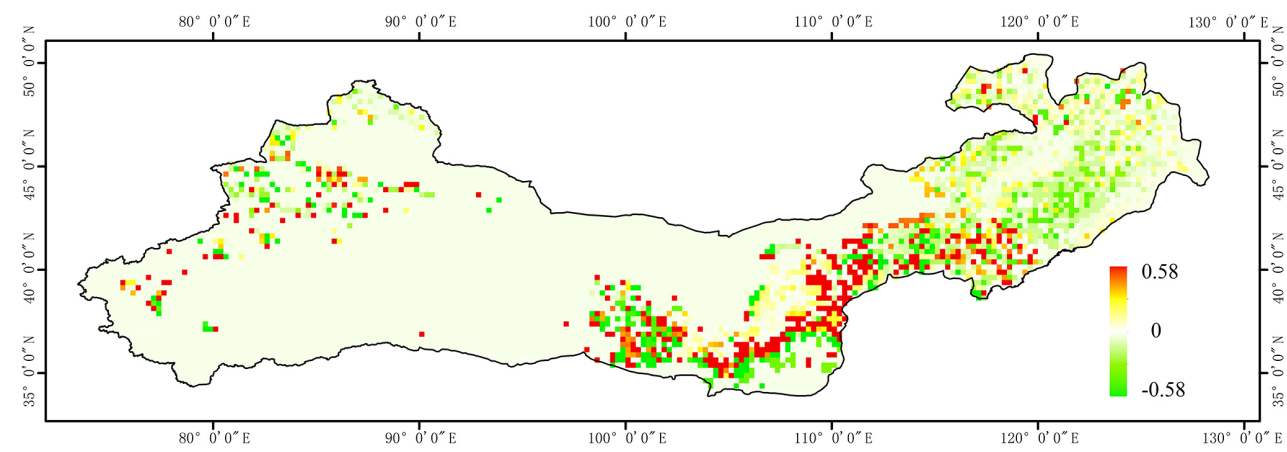

Figure 3. Differences of emission flux $\left(E_{2010}-E_{1982}\right.$, micromoles $\left.\mathrm{m}^{-2} \mathrm{~h}^{-1}\right)$ of isoprene between 1982 and 2010 . The emission fluxes in these 2 years are shown in Fig. S2a and b in the Supplement.
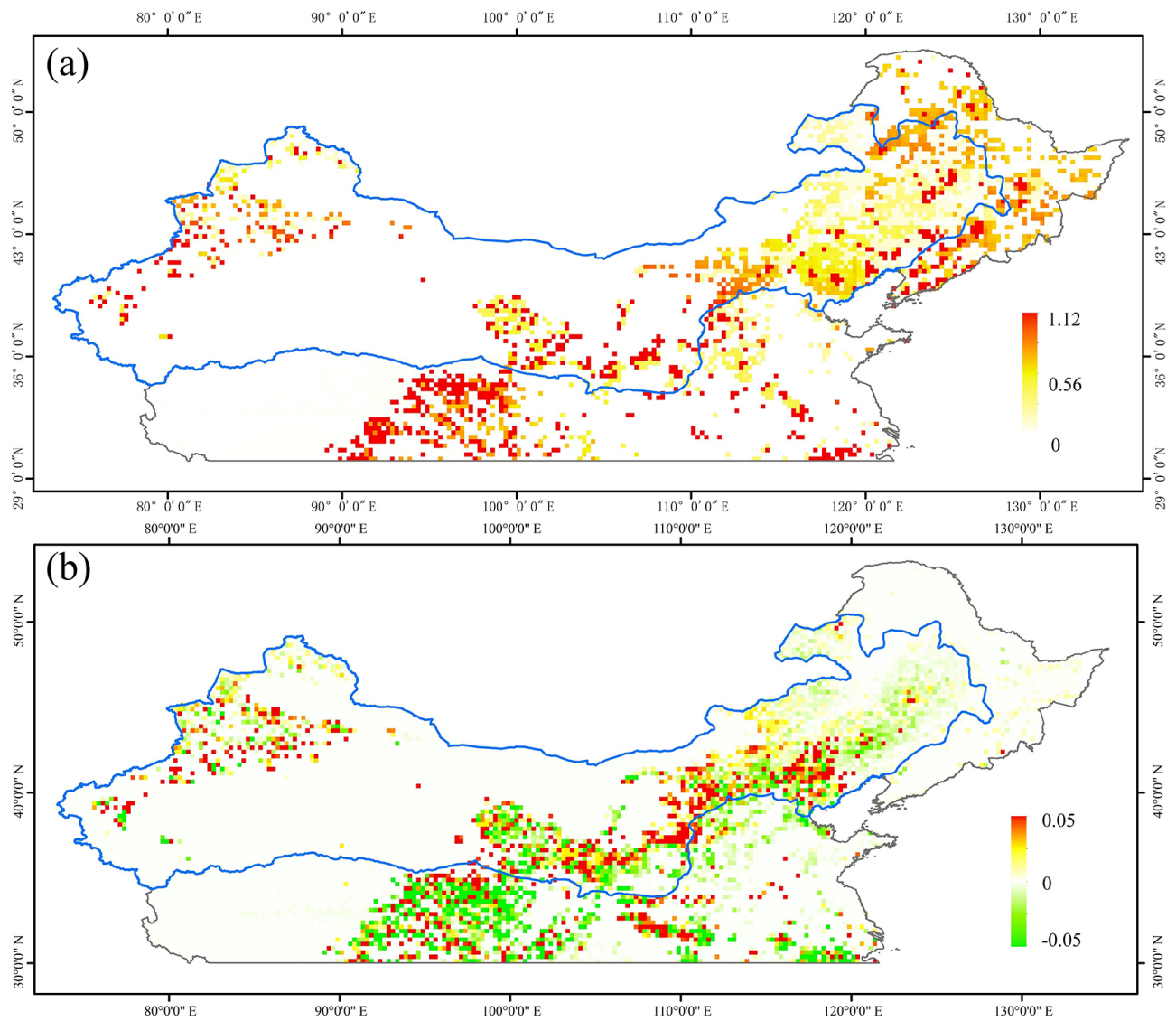

Figure 4. (a) Gridded annual isoprene biogenic emissions (micromoles $\mathrm{m}^{-2} \mathrm{~h}^{-1}$ ) in the year 2000 over northern China with spacing $1 / 4^{\circ} \times 1 / 4^{\circ}$ latitude/longitude; (b) slopes of linear regression relationships between annual mean isoprene emission flux (micromoles $\mathrm{m}^{-2} \mathrm{~h}^{-1}$ ) and the time sequence (or linear trend) from 1982 to 2010 across northern China.

the northeast Qinghai province to the Ta-pa Mountains, the boreal forest in northeast China, central north China, and the Tianshan Mountain and Pamirs in the Xinjiang province. The spatial pattern of the estimated emissions in northeastern China is similar to Song et al. (2012)'s results from 2008 to 2010 (Song et al., 2012). They showed high isoprene emissions from the boreal forest in northeastern China and Qinling-Ta-pa mountains.
The total annual isoprene emission, summed from annual emissions of the model grids that fall within the TNRSF domain, ranged from 45000 to $70000 \mathrm{t} \mathrm{yr}^{-1}$ during 19822010 for the whole TNRSF (the area encircled by the blue solid line in Fig. 4), and from 132000 to $176000 \mathrm{t} \mathrm{yr}^{-1}$ for all of northern China (Fig. 4). This is equivalent to a total emission of 1.6 and $4.4 \mathrm{Tg}$, respectively, for the two regions during the past 3 decades from 1982 to 2010 . It is worth 


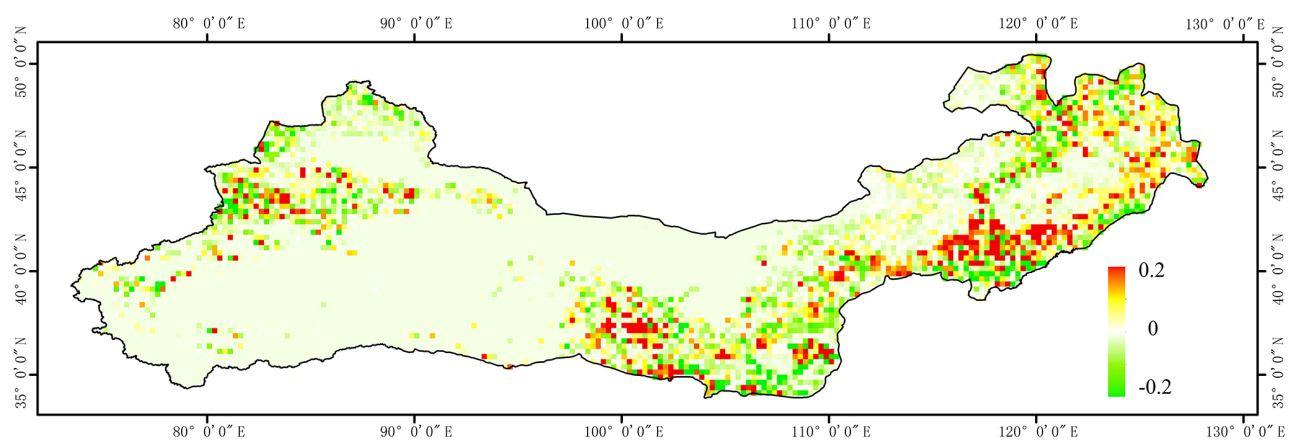

Figure 5. Slopes of linear regression relationships between summer mean isoprene emission flux (micromoles $\mathrm{m}^{-2} \mathrm{~h}^{-1}$ ) and the time sequence (or linear trend) from 1982 to 2010 across the TNRSF.

noting that, although the TNRSF accounts for $59 \%$ of the total area of northern China and $42 \%$ of mainland China (Zhang et al., 2015), it covers almost all arid and semi-arid regions in northern China. Vegetation coverage in these regions was still sparse after 30 years of construction of the TNRSF, and shrubs, instead of trees, are major plant types in the northwest China region of the TNRSF. The isoprene emissions are considerably low in these regions, as shown by Figs. 4 and 5 . In addition, as shown by Fig. 4, the region of northern China defined in this study extends virtually to $30^{\circ} \mathrm{N}$. Although the isoprene emissions in the TNRSF only accounted for $37 \%$ of the total emissions in northern China, the relatively strong increasing trend (Fig. 2) in the TNRSF (slope $=0.881, R^{2}=0.335$ ) has reversed the negative trend (slope $=-0.533, R^{2}=0.05$ ) of the total annual isoprene emissions in northern China, which did not take the isoprene emissions in the TNRSF into consideration, to the positive trend (slope $=0.347, R^{2}=0.014$ ) from 1982 to 2010 in northern China, as shown in Fig. S3.

To highlight the contribution of the TNRSF to the increasing isoprene emissions, the trend of the gridded isoprene emissions over the TNRSF was further investigated. As expected, the estimated monthly emission fluxes showed dramatic seasonal variations with the largest values in summer and the lowest values in winter, consistent with the seasonal changes in LAI over the TNRSF (figure not shown). Figure 5 presents the gridded trends of the summer biogenic isoprene emissions across the TNRSF from 1982 to 2010. The summer emission fluxes exhibited a similar annual pattern to the annual emissions (Fig. 4b) but were greater than the annual emissions, as shown by Fig. 5. Positive trends of the emissions were observed in the mountainous and surrounding areas of the Junggar Basins (north Xinjiang), eastern Qinghai province in the northwest China region of the TNRSF, the central north China region, and the western Liaoning province in the northeast China region of the TNRSF. These provinces and locations are marked in Fig. 1. In particular, the largest positive trends can be observed in the areas north of the two megacities - Beijing and Tianjin. These two megacities have been targeted as key cities to be protected by the TNRSF from sandstorms from the north. Extensive tree planting activities have been promoted to the north of these two megacities (Central Government of China, 2012).

Figure 6 shows the isoprene emissions from 1982 to 2010 averaged over northwest China, the central north China, and the northeast China regions of the TNRSF, respectively. It can be identified again that the domain-averaged isoprene emissions in the central north China region of the TNRSF exhibited a clear increasing trend with the slope of 0.0004 ( $\left.R^{2}=0.35, p=0.002\right)$, whereas statistically insignificant and relatively weak trends of isoprene emissions were found in the northeast China (slope $=0.00003, R^{2}=0.032, p=$ 0.484 ) and northwest China (slope $=0.00009, R^{2}=0.27$, $p=0.012$ ) regions of the TNRSF, respectively. The increase of isoprene emissions over the central north China region can be attributed to continuous expansion of forest coverage. Compared with the central north region of the TNRSF, the forests in the northeast China region are mixed with natural forests. These natural forests already reached the steady state before the 1980s, so they would not contribute to the increasing trend of biogenic isoprene emissions. As shown by Fig. $4 \mathrm{~b}$, the isoprene emissions in most places of northeast China show almost no trends. The northwest China region of the TNRSF is arid and semi-arid area with low precipitation. Shrubs, instead of trees, were planted in many places of this part of the TNRSF regions, resulting in low biogenic isoprene emissions.

Trends of isoprene emissions were also compared between those within and outside the TNRSF and in natural forests. Three small areas were selected for the comparison, each consisting of four grid points, in the central north China region of the TNRSF (marked by the red circle in the inner map of Fig. 1), a farmland outside the TNRSF (blue circle), and in the boreal forest of northeast China (the Greater Khingan mountains, marked by a yellow circle in Fig. 1), respectively. Trends in annually averaged isoprene emissions from these three small areas are shown in Fig. 7. A significant increasing trend is only seen in the area within the TNRSF. The levels of isoprene emissions in the other two small areas were almost uniformly distributed for the last 3 decades. 


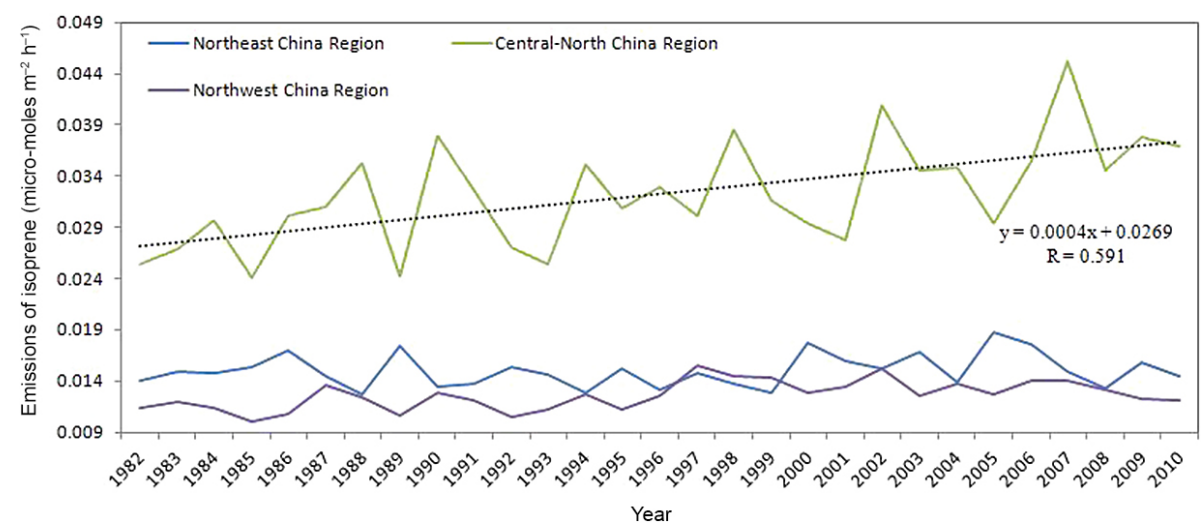

Figure 6. Annual variations of emission fluxes of isoprene averaged over three regions of the northeast, central north, and northwest China region of the TNRSF. The dotted straight line represents linear trend of isoprene emission fluxes in the central north China region.

\subsection{Comparison with the previous emission data}

No extensive and direct measurements of BVOC emissions across the TNRSF have been ever carried out. Several field campaigns were conducted to measure BVOC emissions in northern China but these monitoring programs were not typically designated for the TNRSF (Klinger et al., 2002; Wang et al., 2003). Li et al. (2013) established an emission inventory of BVOCs (isoprene, monoterpenes, sesquiterpene and other VOCs) over China using MEGAN2.1 model. Their results showed that annually averaged isoprene emission fluxes ranged from 0 to $22 \mu \mathrm{g} \mathrm{m}^{-2} \mathrm{~h}^{-1}$ in 2003 in northern Xinjiang, Qinghai, Gansu, and Shaanxi provinces in the northwest China region of the TNRSF, and western inner Mongolia. The average isoprene emission fluxes estimated in the present study for the same regions and the same year ranged from 0.01 to $18.2 \mu \mathrm{g} \mathrm{m}^{-2} \mathrm{~h}^{-1}$, agreeing reasonably well with Li et al. (2013)'s data. Li et al. (2013)'s inventory also showed high isoprene emission flux in the central north China region, including the north of Shanxi and Hebei provinces, Beijing, and the natural (boreal) forest area in northeast China, ranging from 22 to $880 \mu \mathrm{g} \mathrm{m}^{-2} \mathrm{~h}^{-1}$. While the lower limit of their estimated flux agrees well with our lowest emission flux of $20.4 \mu \mathrm{g} \mathrm{m}^{-2} \mathrm{~h}^{-1}$, the upper limit of their emission flux was $880 \mu \mathrm{g} \mathrm{m}^{-2} \mathrm{~h}^{-1}$, is a factor of 4 higher than our value $\left(122.4 \mu \mathrm{g} \mathrm{m}^{-2} \mathrm{~h}^{-1}\right)$ for the same region. Li et al. (2013) adopted more locally updated species-specific emission factors and a vegetation classification based on a new vegetation investigation in the late 1990s and early 2000s in China. Their calculation also used hourly and diurnal meteorological (temperature, radiation, winds) data. Our estimated fluxes used the emission factors specified in the MEGAN2.1 (Guenther et al., 2012) and vegetation types classified by the roughness lengths (Zhang et al., 2002, 2015). In addition, our model input daily meteorological data. These different input data to the MEGAN model likely resulted in the difference of the isoprene emission fluxes between Li et al. (2013) and our results. Song et al. (2012) simulated BVOC emissions in eastern China from 2008 to 2010. A portion of their model domain in eastern China was superimposed with the central north and the northeast China regions of the TNRSF defined in our study. The annually averaged isoprene emission fluxes from 2008 to 2010 from Song et al. (2012)'s model simulations ranged from 10 to $100 \mu \mathrm{g} \mathrm{m}^{-2} \mathrm{~h}^{-1}$ in the inner Mongolia region, and $100-1000 \mathrm{~g} \mathrm{~m}^{-2} \mathrm{~h}^{-1}$ in the north of the Shanxi and Hebei provinces, Beijing, and Tianjin, which were higher than our results of 0 to $32.6 \mu \mathrm{g} \mathrm{m}^{-2} \mathrm{~h}^{-1}$ and 20.4 to $122.4 \mu \mathrm{g} \mathrm{m}^{-2} \mathrm{~h}^{-1}$, respectively, in these two regions. Song et al. (2012) used MEGAN2.04 model with different emission factors adjusted based on China's principal vegetation species (Song et al., 2012). These could also lead to different biogenic isoprene emissions.

\section{Discussions}

Overall the estimated biogenic isoprene emission fluxes across the TNRSF illustrated an increasing trend from the 1980s onward (Fig. 2). The incline trend was most significant in the central north region of the TNRSF where most intensive afforestation has been carried out in north China (Zheng and Zhu, 2013), in order to protect the national capital (Beijing) region from dust and sandstorms. The increasing biogenic isoprene emissions can be attributed to the development of the TNRSF. The forest expansion in the TNRSF can be identified by the satellite-derived LAI, as seen in Fig. S4a and $b$. The linear increasing trend of the LAI across the TNRSF is consistent with the modeled isoprene emission fluxes. The maximum increase $(58 \%)$ of the isoprene emissions from 1982 to 2010 in the central north region of the TNRSF seems to agree well with the model prediction by Arneth et al. $(2008,2011)$ based on projected land use changes. Their modeling results suggested that increasing forest area could lead to several tens of percent of change in biogenic isoprene emissions. 


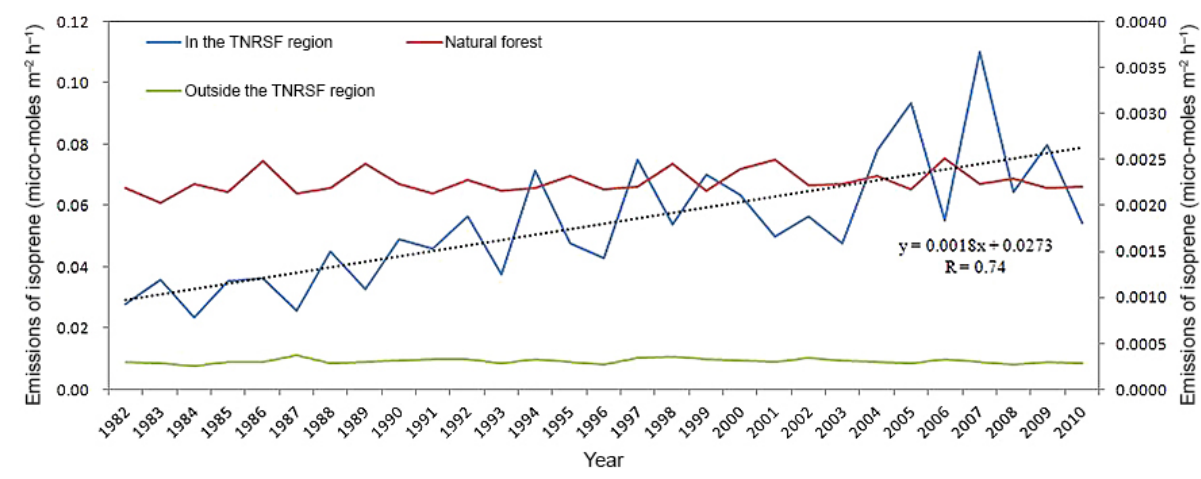

Figure 7. Annual variation and trend of isoprene emission flux spatially averaged over three small areas in and outside the TNRSF in central north China and the natural (boreal) forest region as marked in Fig. 1. The left-hand side $y$ axis scales the trend of isoprene emission fluxes in the TNRSF region and boreal forest in northeast China and the right-hand side $y$ axis scales the emission flux from the farmland outside the TNRSF.

As shown above, the significant incline trend of the annual total isoprene emissions in the TNRSF has affected the longterm trend of the emissions in northern China. This implies that the increasing emission trends across the TNRSF could alter the large-scale BVOC emissions not only in the TNRSF but also in northern China considering that the TNRSF occupies $59 \%$ of northern China and $42 \%$ of all of mainland China. Future impacts of the TNRSF on BVOC emissions may be even stronger with continuous increases of vegetation coverage till the end of the program in 2050.

While BVOC emissions vary on short timescales, the global BVOC emissions are often assumed to change little on a long-term (e.g., decadal) scale (Purves et al., 2004; Sindelarova et al., 2014) considering the steady state of global forests. Since BVOCs can partition onto or form particles in the atmosphere after oxidation, their emissions could affect aerosol formation, cloud condensation nuclei, and climate (Makkonen et al., 2012; Penuelas and Staudt, 2010). Identification of the impact of climate change on BVOC emissions is not straightforward if regional or global forests reach a steady state. The evidence identified in this study suggested that the human-induced BVOC emissions via large-scale afforestation exert strong influence on long-term BVOC emissions and should be taken into consideration in projected climate change scenarios, at least on a regional scale, such as in northern China. As a precursor of secondary organic aerosols and tropospheric ozone, the significant incline of biogenic isoprene emissions also carries significant implications to the air quality in northern China. Heavy air pollution in the Beijing-Tianjin-Hebei area (Fig. 1) has been widely known nationally and internationally, characterized by yearround high levels of fine particular matter $\left(\mathrm{PM}_{2.5}\right)$ and high surface ozone concentrations in the summertime. The Chinese government has decided to extend the TNRSF as one of the primary measures to reduce and remove air pollutants from the Beijing-Tianjin-Hebei area (Chinese Environmental Protection Agency, 2013). As shown in Figs. 5 and 6, the
TNRSF in the central north region covering a large part of the Beijing-Tianjin-Hebei area has already gained the most rapid development as compared to the other two northern regions of the TNRSF (Fig. 1), leading to marked incline of isoprene emissions. However, it is not yet clear if and how the extension of the TNRSF could otherwise improve local air quality. Our previous study suggested that the TNRSF played a moderate role in removing $\mathrm{SO}_{2}$ and $\mathrm{NO}_{x}$ (Zhang et al., 2015). Under the rapidly increasing $\mathrm{NO}_{x}$ emissions in the past decade due to the rapidly increasing number of private vehicles in the Beijing-Tianjin-Hebei area, it is necessary to assess the interactions between BVOC emissions from the TNRSF and local air quality in this region.

In addition to its long-term trend, isoprene emissions also exhibited short-term interannual fluctuations, as also observed in Fig. 2. Factors causing the fluctuations or interannual changes in the emission fluxes depend on meteorological and biological processes. Afforestation and deforestation often took place during the course of the TNRSF construction due to favorable or unfavorable weather and climate conditions for tree growth. For example, $10-50 \%$ of trees planted since the late 1970 s in the central north region of the TNRSF were reported dead since 2007 (Zhang et al., 2013; Tan and Li, 2015), causing visible decline of the forest coverage and isoprene emissions in this region after 2007, as shown in Fig. 2. The lower isoprene emissions in 2010 in the northeast China region and eastern inner Mongolia region of the TNRSF as compared with those in 1982 were inconsistent with the increasing trend of the emissions. The forest coverage in the northeast China region did not show considerable change between 1982 and 2010. On the other hand, lower annual temperatures (e.g., by around $1{ }^{\circ} \mathrm{C}$ ) in 2010 were evident over the northeast China region of the TNRSF than those in 1982, as shown by the differences of annual surface temperatures (SATs, ${ }^{\circ} \mathrm{C}$ ) between 1982 and $2010\left(T_{\text {dif }}=T_{2010}-T_{1982}\right.$, Fig. S5a $)$, which likely caused lower biogenic emissions in 2010 (Purves et al., 
2004; Arneth et al., 2008, 2011). Negative $T_{\text {dif }}$ in the northeast China region of the TNRSF corresponded nicely to negative $E_{\text {dif }}$ (Fig. 3), indicating the strong association between SATs and isoprene emissions. In addition, compared with the increasing trend of LAI in the northeastern China region of the TNRSF (Fig. S4a), no statistically significant increasing trends of the isoprene emissions are discerned in this region. Figure S5b displays the trend of annual SATs in the northeast China region of the TNRSF from 1982 to 2010 . Overall the SATs exhibited a decreasing trend, caused mostly by declining SATs since the late 1990s. Since temperature plays a key role in canopy BVOC emissions (Guenther et al., 2012; Li et al., 2013), the lack of the incline trend of the isoprene emission fluxes in the northeast China region of the TNRSF might be attributable to the decreasing SAT from the late 1990s.

Another environmental factor that may exert the influence on the trend of isoprene emissions is solar radiation/PAR (Situ et al., 2014). Analogous to the response of the BVOC emissions to temperature, increasing radiation could also enhance the isoprene emissions, or vice versa, particularly on a daily or monthly basis. To elucidate potential association between the long-term trend of biogenic isoprene emissions and PAR, we estimated the trend of the flux of PAR (Guenther et al., 1995) over the TNRSF from 1982 to 2010. Results are shown in Fig. S6. Positive trends can be observed in the northwest China region of the TNRSF (Xinjiang, Gansu) and inner Mongolia. In contrast to the positive trends of isoprene emissions in the central north China region of the TNRSF, PAR in this region exhibited negative trends. Hu et al. (2010) have calculated the long-term changes in PAR in Beijing using a broadband global solar radiation data set. Their result revealed a significant declining trend of PAR from the late 20th century. They attributed the decrease of PAR to increasing aerosol emissions from large amounts of fossil fuel combustion due to rapid economic development and industrialization in north China, including the Beijing-Tianjin-Hebei region, in the past several decades. The increase in anthropogenic aerosol particles can both absorb and scatter solar radiation in the atmosphere, contributing to the decreasing PAR. Within and proximate to north China where most heavy industries in China are located, the central north China region is the mostly contaminated area in the TNRSF by particulate matter and other air pollutants. Higher aerosol loading to this region was at least partially responsible for the decrease in the trend of PAR. This means that, while PAR contributes significantly to daily and monthly changes as well as spatial distribution in biogenic isoprene emissions in the TNRSF, it is unlikely to overwhelm the long-term trend of isoprene emissions.

The comparison between the isoprene emission trends and the emissions in 2000 in northern China also carries a significant implication for the human-induced BVOC emissions. As shown in Fig. 4b, the trend of isoprene emissions from 1982 to 2010 over northern China showed a rather different spatial pattern from its emissions in 2000 (Fig. 4a). No signif- icant trends were observed in the boreal forest in northeastern China, though a larger amount of isoprene was emitted from the forest in this region in 2000. This implies that this natural forest was likely under a steady state from which the biogenic isoprene emissions were not altered on the decadal basis (Sanderson et al., 2003; Purves et al., 2004).

Although the Qinling-Ta-pa mountains exhibited the highest emissions in 2000 (Fig. 4a), negative trends of the biogenic isoprene emissions dominated this area, indicating the declining of the emissions over the period of 1982-2010. This is consistent with the decreasing vegetation coverage during this period in this region, as shown by the negative trends of the LAI in northern China (Fig. S4). On the other hand, most positive trends of LAI can be identified in the central north region and along the foot of Tianshan Mountain in west China (see the areas encircled by the solid blue line in Fig. 4). This manifests that the TNRSF exerts strong influences on biogenic VOC emissions, particularly on their decadal variation, though the magnitude of emissions might not be higher than that from natural forests in northeast China (Fig. 4a). Results further imply that the TNRSF is very likely the major source contributing to the increasing biogenic isoprene emissions over the past 30 years and for many years to come in northern China. Climate change has been thought also to play an important role in the changes in the biogenic emissions of isoprene on decadal or longer timescales because it can alter temperature and vegetation coverage (Turner et al., 1991; Sanderson et al., 2003). It is unknown if and to what extent the increasing vegetation coverage and temperature over the TNRSF were induced by climate change. Evidence shows that the human-induced afforestation contributed mostly to the increased vegetation coverage over the TNRSF and northern China (Wang et al., 2011), as shown by Fig. S4a, and hence to the increased biogenic isoprene emissions.

Among the three small areas within the TNRSF, in the farmland, and in the boreal forest of northeast China (Fig. 7), the emission values increased by nearly 5 times from 1982 to 2010 in the area within the TNRSF with the slope of 0.0018 $\left(R^{2}=0.55\right)$. On the other hand, no statistically significant increasing trends of biogenic isoprene emissions were found in the farmland and the boreal forest, though the higher emissions were observed in the boreal forest. More interestingly, the biogenic isoprene emissions in the selected small area of the central north China region tend to surpass the isoprene emissions in the boreal forest from 2004 onward. This can be partly attributed to rapidly growing forest coverage and higher temperatures in this region as compared to northeastern China. The large area of foliage trees planted in this region also played a role for relatively high and increasing isoprene emissions as compared with the boreal forests in northeastern China where coniferous trees are major tree species which release relatively lower isoprene to the atmosphere as compared to broadleaf trees in the selected area in the central north China region of the TNRSF (Guenther et al., 2012). 


\section{Conclusions}

Gridded monthly and annual biogenic isoprene emissions in northern China were modeled for the period of 1982-2010 and were then applied to assess the long-term trends of the biogenic isoprene emissions in the TNRSF in order to discriminate the signals of the human activities in decadal and longer-term trends of BVOCs on large spatial scales. Significant impacts of the TNRSF on the BVOC emissions in northern China were identified during the past 3 decades. Annual isoprene emissions in many places of the TNRSF region, especially in the central north China region, exhibited an inclining trend. The maximum increase in the isoprene emission flux reached $58 \%$ between 1982 and 2010, indicating important roles of the human activities on BVOC emissions. The comparison of isoprene emission fluxes among the central north China region of the TNRSF, farmland, and the boreal forest in northeastern China outside the TNRSF revealed that the biogenic isoprene emissions in some areas of the central north China region of the TNRSF produced by man-made forests have surpassed the emissions from the natural forests. This suggests that the TNRSF was a main contributor to the decadal or longer-term changes in BVOCs in northern China. The impact of the TNRSF on BVOC emissions is expected to be stronger in the coming years along with continuous development of the TNRSF program till 2050. Since BVOCs are a major precursor of tropospheric ozone, future studies are needed to investigate how the increased BVOCs in the TNRSF contribute to ozone formation, especially in the case of concurrently increasing $\mathrm{NO}_{x}$ emissions in northern China.

\section{Data availability}

The meteorological data used in the MEGAN2.1 model compiled by NCEP Final Operational Global Analysis are available at http://rda.ucar.edu/datasets/ds083.2/ (National Centers for Environmental Prediction, 2016).

\section{The Supplement related to this article is available online at doi:10.5194/acp-16-6949-2016-supplement.}

Acknowledgements. This work is supported by the National Natural Science Foundation of China through grants 41371478 and 41371453.

Edited by: A. B. Guenther

\section{References}

Adon, M., Galy-Lacaux, C., Delon, C., Yoboue, V., Solmon, F., and Kaptue Tchuente, A. T.: Dry deposition of nitrogen compounds $\left(\mathrm{NO}_{2}, \mathrm{HNO}_{3}, \mathrm{NH}_{3}\right)$, sulfur dioxide and ozone in west and central African ecosystems using the inferential method, Atmos. Chem. Phys., 13, 11351-11374, doi:10.5194/acp-13-11351-2013, 2013.

Arneth, A., Schurgers, G., Hickler, T., and Miller, P. A.: Effects of species composition, land surface cover, $\mathrm{CO}_{2}$ concentration and climate on isoprene emissions from European forests, Plant Biol., 10, 150-162, 2008.

Arneth, A., Schurgers, G., Lathiere, J., Duhl, T., Beerling, D. J., Hewitt, C. N., Martin, M., and Guenther, A.: Global terrestrial isoprene emission models: sensitivity to variability in climate and vegetation, Atmos. Chem. Phys., 11, 8037-8052, doi:10.5194/acp-11-8037-2011, 2011.

Ashworth, K., Wild, O., and Hewitt, C. N.: Sensitivity of isoprene emissions estimated using MEGAN to the time resolution of input climate data, Atmos. Chem. Phys., 10, 1193-1201, doi:10.5194/acp-10-1193-2010, 2010.

Aydin, Y. M., Yaman, B., Koca, H., Dasdemir, O., Kara, M., Altiok, H., Dumanoglu, Y., Bayram, A., Tolunary, D., Odabasi, M., and Elbir, T.: Biogenic volatile organic compound (BVOC) emissions from forested areas in Turkey: Determination of specific emission rates for thirty-one tree species, Sci. Total Environ., 490, 239-253, 2014.

Calfapietra, C., Fares, S., Manes, F., Morani, A., Sgrigna, G., and Loreto, F.: Role of biogenic volatile organic compounds (BVOC) emitted by urban trees on ozone concentration in cities: A review, Environ. Pollut., 183, 71-80, 2013.

Camporn, S. J.: Ecophysiological Responses of Plants to Air Pollution, Manchester Metropolitan University, Manchester, UK, doi:10.1002/9780470015902.a0003206.pub2, 2013.

Central Government of China: Forest cover area from artifcial afforestation in the Three Northern Regions Shelter Forest regions, available at: http://www.gov.cn/jrzg/2012-08/27/content_ 2211594.htm (last access: 3 June 2016), 2012 (in Chinese).

Chang, K. H., Yu, J. Y., Chen, T. F., and Lin, Y, P.: Estimating Taiwan biogenic VOC emission: Leaf energy balance consideration, Atmos. Environ., 43, 5092-5100, 2009.

Chen, Y., Li, D. W., Shi, Y., and He, X.: Emission rate of biogenic volatile organic compounds from urban trees in Shenyang, China, Journal of Northeast Forestry University, 37, 47-49, 2009 (in Chinese).

Cheng, D. and Gu, J.: Influence of the Three Northern Regions Shelter Forest on micro-scale climate, in: Ecological Benefit and Physical Characteristics of Atmospheric Boundary-layer of the Three Northern Regions Shelter Forest, edited by: Zhu, T., Meteorological Publisher of China, Beijing, China, 209-216, 1992 (in Chinese).

Chinese Environmental Protection Agency: Action plans for implementing air pollution control strategy, available at: http://www. zhb.gov.cn/gkml/hbb/bwj/201309/t20130918_260414.htm (last access: 3 June 2016), 2013 (in Chinese).

Constable, J. V. H., Guenther, A. B., Schimel, D. S., and Monson, R. $\mathrm{K}$.: Modelling changes in VOC emissions in response to climate change in the continental United States, Glob. Change Biol., 5, 791-806, 1999. 
Ding, Y., Li, Q., and Dong, W.: A numerical assessment of effect of forest coverage on regional climate in China, J. Meteorol. Res., 63, 613-621, 2005 (in Chinese).

Fang, J. Y., Chen, A. P., Peng, C. H., Zhao, S. Q., and Ci, L. J.: Changes in forest biomass carbon storage in China between 1949 and 1998, Science, 292, 2320-2322, 2001.

Fenn, M. E., Ross, C. S., Schilling, S. L., Baccus, W. D., Larrabee, M. A., and Lofgren, R. A.: Atmospheric deposition of nitrogen and sulfur and preferential canopy consumption of nitrate in forests of the Pacific Northwest, USA, Forest Ecol. Manag., 302, 240-253, 2013.

Geron, C., Guenther, A., Greenberg, J., Karl, T., and Rasmussen, R.: Biogenic volatile organic compound emissions fromdesert vegetation of the southwestern US, Atmos. Environ., 40, 1645-1660, 2006.

Guenther, A., Hewitt, C. N., Erickson, D., Fall, R., Geron, C., Graedel, T., Harley, P., Klinger, L., Lerdau, M., Mckay, W. A., Pierce, T., Scholes, B., Steinbrecher, R., Tallamraju, R., Taylor, J., and Zimmerman, P.: A global-model of natural volatile organic-compound emissions, J. Geophys. Res.-Atmos, 100, 7392, 1995.

Guenther, A., Karl, T., Harley, P., Wiedinmyer, C., Palmer, P. I., and Geron, C.: Estimates of global terrestrial isoprene emissions using MEGAN (Model of Emissions of Gases and Aerosols from Nature), Atmos. Chem. Phys., 6, 3181-3210, doi:10.5194/acp-63181-2006, 2006.

Guenther, A. B., Jiang, X., Heald, C. L., Sakulyanontvittaya, T., Duhl, T., Emmons, L. K., and Wang, X.: The Model of Emissions of Gases and Aerosols from Nature version 2.1 (MEGAN2.1): an extended and updated framework for modeling biogenic emissions, Geosci. Model Dev., 5, 1471-1492, doi:10.5194/gmd-51471-2012, 2012.

Guo, P. P., Guo, K. J., Ren, Y., Shi, Y., Chang, J., Tani, A., and Ge, Y.: Biogenic volatile organic compound emissions in relation to plant carbon fixation in a subtropical urban-rural complex, Landscape Urban Plan., 119, 74-84, 2013.

Hanna, S. R., Russell, A. G., Wilkinson, J. G., Vukovich, J., and Hansen, D. A.: Monte Carlo estimation of uncertainties in BEIS3 emission outputs and their effects on uncertainties in chemical transport model predictions, J. Geophys. Res., 110, 372-384, 2005.

Helmig, D., Daly, R. W., Milford, J., and Guenther, A.: Seasonal trends of biogenic terpene emissions, Chemosphere, 93, 35-46, 2013.

$\mathrm{Hu}, \mathrm{D}$., Wang, R., and Liu, G.: Long-term trends in photosynthetically active radiation in Beijing, Adv. Atmos. Sci., 27, 13801388,2010

Hu, H., Wang, H., Lu, X., and Qiu, Z.: Assessment of influence of shelter forest on climate in arid and semi-arid regions in China, J. Nanjing Forestry University (Natural science), 25, 77-82, 2001 (in Chinese).

Klinger, L. F., Li, Q. J., Guenther, A., B., Greenberg, J. P., Baker, B., and Bai, J.: Assessment of volatile organic compound emissions from ecosystems of China, J. Geophy. Res., 107, 4603, doi:10.1029/2001JD001076, 2002.

Lamb, B., Guenther, A., Gay, D., and Westberg, H.: A national inventory of biogenic hydrocarbon emissions, Atmos. Environ., 21, 1695-1705, 1987.
Li, L. Y., Chen, Y., and Xie, S. D.: Spatio-temporal variation of biogenic volatile organic compounds emissions in China, Environ. Pollut., 182, 157-168, 2013.

Liu, Y. Q., Stanturf, J. A., and Lu, H. Q.: Modeling the potential of the northern China Forest Shelterbelt in improving hydroclimate conditions, J. Am. Water Resour. As., 44, 1176-1192, 2008.

Makkonen, R., Asmi, A., Kerminen, V.-M., Boy, M., Arneth, A., Guenther, A., and Kulmala, M.: BVOC-aerosol-climate interactions in the global aerosol-climate model ECHAM5.5-HAM2, Atmos. Chem. Phys., 12, 10077-10096, doi:10.5194/acp-1210077-2012, 2012.

Müller, J.-F., Stavrakou, T., Wallens, S., De Smedt, I., Van Roozendael, M., Potosnak, M. J., Rinne, J., Munger, B., Goldstein, A., and Guenther, A. B.: Global isoprene emissions estimated using MEGAN, ECMWF analyses and a detailed canopy environment model, Atmos. Chem. Phys., 8, 1329-1341, doi:10.5194/acp-81329-2008, 2008.

Myles, L., Heuer, M. W., Meyers, T. P., and Hoyett, Z. J: A comparison of observed and parameterized $\mathrm{SO}_{2}$ dry deposition over a grassy clearing in Duke Forest, Atmos. Environ., 49, 212-218, 2012.

National Centers for Environmental Prediction: Final operational Global Analysis, available at: http://rda.ucar.edu/datasets/ds083. 2/, last access: 3 June 2016.

Nichol, J. and Wong, M. S.: Estimation of ambient BVOC emissions using remote sensing techniques, Atmos. Environ., 45, 2937 2943, 2011.

Nowak, D. J., Crane, D. E., and Stevens, J. C.: Air pollution removal by urban trees and shrubs in the United States, Urban For. Urban Gree., 4, 115-123, 2006.

Nowak, D. J., Hirabayashi, S., Bodine, A., and Greenfield, E.: Tree and forest effects on air quality and human health in the United States, Environ. Pollut., 193, 119-129, 2014.

Pacifico, F., Harrison, S. P., Jones, C. D., and Sitch, S.: Isoprene emissions and climate, Atmos. Environ., 43, 6121-6135, 2009.

Pang, Q.: Construction of the Three Northern Regions Shelter Forest in China, Forestry Publisher of China, Beijing, China, 1992 (in Chinese).

Parungo, F., Li, Z., Li, X., Yang, D., and Harris, J.: Gobi dust storms and the Great Green Wall, Geophys. Res. Lett., 21, 999-1002, 1994.

Penuelas, J. and Staudt, M.: BVOCs and global change, Trends Plant Sci., 15, 133-144, 2010.

Penuelas, J., Rutishauser, T., and Filella, I.: Phenology feedbacks on climate change, Science, 324, 887-888, 2009.

Pfister, G. G., Emmons, L. K., Hess, P. G., Lamarque, J. F., Orlando, J. J., Walters, S., Guenther, A., Palmer, P. I., and Lawrence, P. J.: Contribution of isoprene to chemical budgets: A model tracer study with the NCAR CTM MOZART-4, J. Geophys. Res.-Atmos., 113, 79-88, 2008.

Purves, D. W., Caspersen, J. P., Moorcroft, P. R., Hurtt, G. C., and Pacala, S. W.: Human-induced changes in US biogenic volatile organic compound emissions: evidence from long-term forest inventory data, Glob. Change Biol., 10, 1737-1755, 2004.

Sakulyanontvittaya, T., Duhl, T., Wiedinmyer, C., Helmig, D., Matsunaga, S., Potosnark, M., Miford, J., and Guenther, A.: Monoterpene and sesquiterpene emission estimates for the United States, Environ. Sci. Technol., 42, 1623-1629, 2008. 
Sanderson, M. G., Jones, C. D., Collins, W. J., Johnson, C. E., and Derwent, R. G.: Effect of climate change in isoprene emissions and surface ozone levels, Geophys. Res. Lett., 30, 159-171, 2003.

Sindelarova, K., Granier, C., Bouarar, I., Guenther, A., Tilmes, S., Stavrakou, T., Müller, J.-F., Kuhn, U., Stefani, P., and Knorr, W.: Global data set of biogenic VOC emissions calculated by the MEGAN model over the last 30 years, Atmos. Chem. Phys., 14, 9317-9341, doi:10.5194/acp-14-9317-2014, 2014.

Situ, S., Wang, X., Guenther, A., Zhang, Y. L., Wang, X. M., Huang, M. J., Fan, Q., and Xiong, Z.: Uncertainties of isoprene emissions in the MEGAN model estimated for a coniferous and broadleaved mixed forest in Southern China, Atmos. Environ., 98, 105-110, 2014.

Song, Y. Y., Zhang, Y. Y., Wang, Q. G., and An, J. L.: Estimation of biogenic VOCs emissions in Eastern China based on remote sensing data, Acta Scientiae Circumstantiae, 32, 22162227, 2012 (in Chinese).

Steiner, A., Luo, C., Huang, Y., and Chameides, W. L.: Past and present-day biogenic volatile organic compound emissions in East Asia, Atmos. Environ., 36, 4895-4905, 2002.

Tan, K., Piao, S., Peng, C., and Fang, J.: Satellite-based estimation of biomass carbon stocks for northeast China's forests between 1982 and 1999, Forest Ecol. Manag., 240, 114-121, 2007.

Tan, M. and Li, X.: Does the Green Great Wall effectively decrease dust storm intensity in China? A study based on NOAA NDVI and weather station data, Land Use Policy, 43, 42-47, 2015.

Turner, D. P., Wones, A. G., Pross, D., and Phillips, D. L.: Climate change and global isoprene emissions, Paper 91-126. 3, Global Climate Change: Papers from the 84th Annual General Meeting of the Air and Waste Management Association, 16-21 June 1991, Vancouver, Canada, 1991.

Wang, Q., Zhang, B., Dai, S. P., Zou, Y., Ma, Z. H., and Zhang, Y. N.: Dynamic changes in vegetation coverage in the Three Northern Regions Shelter Forest Program based on GIMMS AVHRR NDVI, Resour. Sci., 33, 1613-1620, 2011 (in Chinese).
Wang, Z. H., Bai, Y. H., and Zhang, S. Y.: A biogenic volatile organic compounds emission inventory for Beijing, Atmos. Environ. 37, 3771-3782, 2003.

Wei, X. L., Li, Y. S., Lam, K. S., Wang, A. Y., and Wang, T. J.: Impact of biogenic VOC emissions on a tropical cyclone-related ozone episode in the Pearl River Delta region, China, Atmos. Environ., 41, 7851-7864, 2007.

Yan, Q. L., Zhu, J. J., Hu, Z. B., and Sun, O. J.: Environmental impacts of the Shelter Forests in Horqin sandy land, Northeast China, J. Environ. Qual., 40, 815-824, 2011.

Zemankova K. and Brechler, J.: Emissions of biogenic VOC from forest ecosystems in central Europe: Estimation and comparison with anthropogenic emission inventory, Environ. Pollut., 158, 462-469, 2010.

Zhang, L., Moran, M. D., Makar, P. A., Brook, J. R., and Gong, S.: Modelling gaseous dry deposition in AURAMS: a unified regional air-quality modelling system, Atmos. Environ., 36, 537560, 2002.

Zhang, X., Huang, T., Zhang, L., Gao, H., Shen, Y., and Ma, J.: Trends of deposition fluxes and loadings of sulfur dioxide and nitrogen oxides in the artificial Three Northern Regions Shelter Forest across northern China, Environ. Pollut., 207, 238-247, 2015.

Zhang, Y., Wang, X., and Qin, S.: Carbon stocks and dynamics in the three-north protection forest program, China, Austrian J. Forest Sci., 130, 25-43, 2013.

Zheng, X. and Zhu, J.: Estimation of shelter forest area in Three Northern Regions Shelter Forest Program region based on multisensor remote sensing data, Chin. J. Appl. Ecol., 24, 2257-2264, 2013.

Zhong, Z., Wang, H., Xiong, W., and Sha, W.: A numerical investigation of association between environment and the Three Northern Regions Shelter Forest: Model evaluation and verification, J. PLA University of Technology, 2, 7-12, 2001 (in Chinese). 